International Journal of Automotive and Mechanical Engineering (IJAME)

ISSN: 2229-8649 (Print); ISSN: 2180-1606 (Online); Volume 8, pp. 1226-1241, July-December 2013

(C) Universiti Malaysia Pahang

DOI: http://dx.doi.org/10.15282/ijame.8.2013.13.0101

\title{
OPTIMIZATION OF THE MATERIAL REMOVAL RATE IN TURNING OF UD-GFRP USING THE PARTICLE SWARM OPTIMIZATION TECHNIQUE
}

\author{
Meenu and Surinder Kumar \\ Department of Mechanical Engineering, National Institute of Technology \\ Kurukshetra-136119, India \\ E-mail: surinder.asd@ gmail.com, \\ Phone Number: 09466267889
}

\begin{abstract}
In this paper the particle swarm optimization technique is applied to experimental results in order to optimize the turning of unidirectional glass fiber reinforced plastics composite with consideration to the material removal rate. Taguchi's $\mathrm{L}_{18}$ orthogonal array is used to conduct experimentation. The parameters considered are tool nose radius, tool rake angle, feed rate, cutting speed, cutting environment (dry, wet, cooled) and depth of cut. ANOVA is used to find out significant parameters (feed rate, cutting speed and depth of cut). The most significant parameters are feed rate and cutting speed. The maximum value of material removal rate is found to be $394.33 \mathrm{~mm}^{3} / \mathrm{sec}$., which is at feed rate $(0.200 \mathrm{~mm} / \mathrm{rev})$, cutting speed $(159.58 \mathrm{~m} / \mathrm{min})$ and depth of cut $(1.3996 \mathrm{~mm})$. PSO is an efficient and effective optimization tool for finding the optimum machining parameters for maximizing MRR. The results give a positive indication of the potential offered by PSO.
\end{abstract}

Keywords: UD-GFRP; particle swarm optimization; Taguchi method; turning; material removal rate; polycrystalline diamond cutting tool.

\section{INTRODUCTION}

Composite structure materials have successfully replaced traditional materials in respect of their high strength, high stiffness, good dimensional stability, higher fracture toughness, higher oxidation and corrosion resistance, directional properties, good resistance to heat, cold moisture and ease of fabrication applications (Bachtiar, Sapuan, \& Hamdan, 2010; Umar, Zainudin, \& Sapuan, 2012). As a result, the use of composites has grown considerably, particularly in the aerospace, aircraft, automobile, sporting goods, transportation, power generation and marine industries. Machining of these materials poses particular problems that are seldom seen with metals, due to the inhomogeneity, anisotropy and abrasive characteristics of the composites (Abrate \& Walton, 1992). Composite materials are two different materials that, when combined together, produce a material with properties that exceed the constituent materials. There are two categories of constituent materials (Gordon \& Hillery, 2002).

1. Reinforcement phase (e.g., fibers): The reinforcements impart their special mechanical and physical properties to enhance the matrix properties.

2. Binder phase (e.g., compliant matrix): The matrix material surrounds and supports the reinforcement materials by maintaining their relative position.

Composite materials may have ceramic, metallic or polymeric matrix. Most engineering materials can be classified into one of four basic categories as metals, ceramics, polymer or composites (Janardhan, 2005; Jeffrey, Tarlochan, \& Rahman, (2011); Adebisi, Maleque, \& Rahman, 2011; Bhaskar, \& Sharief, 2012). Fiber-reinforced plastics 
(FRP) have been widely used in industry due to their excellent properties such as high specific modulus, specific strength and damping capacity. They are being commonly used in the aerospace and automotive industries, marine applications, sporting goods and biomedical components. Most of the FRP components are manufactured by molding operations almost to the final size of the desired product. However, postproduction machining is sometimes needed to remove excess material at the edge of the component by trimming and to drill holes for dimensional tolerance and assembly requirements. However, it has been reported that the strong anisotropy and inhomogeneity of FRP introduces many specific problems in machining, such as fiber pullout, delamination, surface damage, burrs and burning (Hu \& Zhang, 2004).The machining of fiber-reinforced materials requires special considerations about the wear resistance of the tool. High speed steel (HSS) is not suitable for cutting owing to the high tool wear and poor surface finish. Hence, carbide and diamond tools are used as suitable cutting tool materials (Paulo Davim \& Reis, 2004; Hariprasad, Dharmalingam, \& Praveen Raj, 2013). Konig et al. (1985) found that measurement of surface roughness in FRP is less dependable than in metal, because protruding fiber tips may lead to incorrect results or at least large variations of the reading. The machined surface of Kevlar fibers reinforced plastics (KFRP) exhibits poor surface finish due to the fussiness caused by delaminated, dislocated and strain ruptured tough Kevlar fibers.

Lee (2001) investigated the machinability of glass fiber reinforced plastics by means of tools made of various materials and geometries. Three parameters, namely cutting speed, feed rate and depth of cut, were selected. Single crystal diamond, poly crystal diamond and cubic boron nitride were used for the turning process. It was concluded that the single crystal diamond tool is excellent for GFRP cutting. Dhavamani and Alwarsamy (2011) presented a new methodology for the optimization of the machining parameters for drilling aluminum silicon carbide (AlSiC). Taguchi's method was used for the experimental design. Three parameters, cutting speed, feed and diameter of cut, were selected to minimize the surface roughness, volume fraction, machining time, metal removal rate, specific energy and flank wear. It was found that the machining performance can be improved effectively through this approach. Murthy, Rodrigues, and Anjaiah (2012) developed a thrust force and torque prediction model for the machining of GFRP composites using response surface methodology by using a solid carbide drill bit. Four parameters, spindle speed, feed, drill diameter and point angle, were selected to minimize the thrust force and torque. It was found that the spindle speed is the main contributing parameter for the variation in the thrust force and that the drill diameter is the main contributing factor for variation in torque. Suresh Kumar Reddy and Venkateswara Rao (2005) developed a surface roughness prediction model for the machining of AISI 1045 steel using a genetic algorithm by using a coated (TiAIN) carbide four fluted end mill cutter. Four parameters, tool geometry (nose radius and radial rake angle) and cutting conditions (cutting speed and feed rate), were selected to minimize the surface roughness. The predictive capability of the surface roughness model was improved by incorporating the tool geometry in the modeling.

Surinder Kumar et al. (2012) developed a cutting force prediction model for the machining of UD-GFRP using regression modeling by using a polycrystalline diamond cutting tool. Three parameters, cutting speed, depth of cut and feed rate, were selected to minimize the cutting force. It was found that the depth of cut is the factor which has the greatest influence on the radial force, followed by the feed rate factor then other parameters, whilst the feed rate is the least significant parameter. Also, the authors concluded that the experimental values agreed with the predicted results, indicating the 
suitability of the multiple regression models. Kumar et al. (2012) investigated the turning process of the unidirectional glass fiber reinforced plastic (UD-GFRP) composites. A polycrystalline diamond (PCD) tool on the turning machine was used and the influence of six parameters, tool nose radius, tool rake angle, feed rate, cutting speed, depth of cut and the cutting environment (dry, wet and cooled (5-7 temperature)), on the surface roughness was measured. It was found that the feed rate is the factor which has the greatest influence on surface roughness, followed by cutting speed. Palanikumar (2008) evaluated the effect of cutting parameters on the surface roughness of the GFRP composites using a PCD tool. Three parameters, cutting speed, feed rate and depth of cut, were selected to minimize the surface roughness. It was found that depth of cut has the least effect on the surface roughness compared to the other parameters. Hussain et al. (2010) developed a surface roughness prediction model for the machining of GFRP pipes using a response surface methodology by using a carbide tool (K20). Four parameters, cutting speed, feed rate, depth of cut and workpiece (fiber orientation), were selected to minimize the surface roughness. It was found that the depth of cut has the least effect on the surface roughness compared to the other parameters. Palanikumar, Latha, Senthilkumar and Karthikeyan (2009) investigation focused on the multiple performance optimizations of machining characteristics of glass fiber reinforced plastics composites by using a non-dominated sorting genetic algorithm. Three parameters, cutting speed, feed rate and depth of cut, were selected to minimize the surface roughness and tool flank wear and to maximize the material removal rate. A polycrystalline diamond tool was used for the turning operation. Khan, Rahman, Kadirgama, Maleque, \& Ishak (2011) proposed an approach for turning of a glass fiber reinforced plastic composites using two different alumina cutting tools: namely, a Ti[C, N] mixed alumina cutting tool (CC650) and a SiC whisker reinforced alumina cutting tool (CC670). Three parameters, cutting speed, depth of cut and feed rate, were selected to minimize the surface roughness. It was found that the performance of the $\mathrm{SiC}$ whisker reinforced alumina cutting tool is better than that of the $\mathrm{Ti}[\mathrm{C}, \mathrm{N}]$ mixed alumina cutting tool for machining GFRP composite. Kennedy and Eberhart (1995) suggested a particle swarm optimization (PSO) based technique for optimization on the analogy of a swarm of birds and a school of fish. The algorithm, which is based on a metaphor of social interaction, searches a space by adjusting the trajectories of moving points in a multidimensional space. The individual particles are drawn stochastically toward the position of present velocity of each individual and the best previous performance of their neighbors (Abido, 2001). The main advantages of the PSO algorithm are summarized as: simple concept, easy implementation, robustness to control parameters and computational efficiency when compared with mathematical algorithms and other heuristic optimization techniques (Dautenhahn, 2002). Zhang and Ishikawa (2008) proposed a new method to prevent premature convergence and for managing the exploration-exploitation trade-off in PSO search, Particle Swarm Optimization with Diversive Curiosity. It was observed that the ratio of success in finding the optimal solution to the given optimization problem was significantly improved and reached $100 \%$ with the estimated appropriate values of parameters in the internal indicator. Zhou et al. (2006) presented a particle swarm optimization technique in training a multi-layer feedforward neural network which was used for a prediction model of diameter error in boring machining. It was observed that the networks for diameter error prediction trained by the PSO algorithm or by the back propagation algorithm both improved the precision of the boring machining, but the neural networks trained by the PSO algorithm performed better than those trained by the back propagation algorithm. 
Verma (2012) used a fuzzy inference system and multi performance characteristic index (MPCI) for modeling and prediction of an FRP-polyester/epoxy composites workpiece. Three parameters, cutting speed, feed rate and depth of cut, were selected to minimize the surface roughness and maximize the material removal rate. It was found that the FIS and MPCI modeling technique can be effectively used for the prediction of the surface roughness and material removal rate in machining of FRP composites. Ravi Sankar, Srikant, Vamsi Krishna, Bhujanga Rao, \& Bangaru Babu, (2013) discussed the comparison between the computational effectiveness and efficiency of the GA and PSO using a formal hypothesis testing approach. The results of this test could prove to be significant for the future development of PSO. It appeared that PSO outperformed the GA with a larger differential in computational efficiency when used to solve unconstrained nonlinear problems with continuous design variables. This paper investigates the optimization problem of the cutting parameters in the turning of unidirectional glass fiber reinforced plastic (UD-GFRP) composite rods. The material removal rate is the response variable. The experiments are performed using a Taguchi $\mathrm{L}_{18}$ orthogonal array. The particle swarm optimization technique is used to find the optimum process parameters.

\section{MATERIAL AND EXPERIMENTAL TECHNIQUE}

Pultrusion processed unidirectional glass fiber reinforced composite rods are used. The fiber used in the rod is E-glass and the resin used is epoxy, while the properties of the material used are shown in Table 1. Workpiece material specimens having a size of 840 $\mathrm{mm}$ in length and $42 \mathrm{~mm}$ in diameter are used. The experiments are carried out on an $\mathrm{NH} 22$ lathe machine with $11 \mathrm{~kW}$ spindle power and a maximum speed of $3000 \mathrm{rpm}$ using a PCD tool. A cutting tool insert with various rake angles $\left(-6^{\circ}, 0^{\circ},+6^{\circ}\right)$ and tool nose radii $(0.4 \mathrm{~mm} \& 0.8 \mathrm{~mm})$ are used. A tool holder SVJCR steel EN47 is used during the turning operation. The experimental results of turning of unidirectional glass fiber reinforced plastics composite are evaluated to ascertain the material removal rate (MRR). The experimental design based on the Taguchi $\mathrm{L}_{18}$ orthogonal method is used.

Table 1. Mechanical and thermal properties of the UD-GFRP material

\begin{tabular}{|c|c|c|c|}
\hline $\begin{array}{l}\text { Sr. } \\
\text { No. }\end{array}$ & Particular & Value & Unit \\
\hline 1 & Glass content (by weight) & $75 \pm 5$ & $\%$ \\
\hline 2 & Epoxy resin content (by weight) & $25 \pm 5$ & $\%$ \\
\hline 3 & Reinforcement, unidirectional & 'E’ Glass Roving & --- \\
\hline 4 & Water absorption & 0.07 & $\%$ \\
\hline 5 & Density & $1.95-2.1$ & $\mathrm{gm} / \mathrm{cc}$ \\
\hline 6 & Tensile strength & 650 & $\left(\mathrm{~N} / \mathrm{mm}^{2}\right)$ \\
\hline 7 & Compression strength & 600 & $\left(\mathrm{~N} / \mathrm{mm}^{2}\right)$ \\
\hline 8 & Shear strength & 255 & $\left(\mathrm{~N} / \mathrm{mm}^{2}\right)$ \\
\hline 9 & Modulus of elasticity & 3200 or $(320)$ & $\left(\mathrm{N} / \mathrm{mm}^{2}\right)$ \\
\hline 10 & Thermal conductivity & 0.30 & $\mathrm{Kcal} / \mathrm{Mhc}^{\circ}$ \\
\hline 11 & Weight of rod $840 \mathrm{~mm}$ in length & 2.300 & Kgs \\
\hline 12 & Electrical strength (radial) & 3.5 & $\mathrm{KV} / \mathrm{mm}$ \\
\hline 13 & Working temperature class & Class 'F' (155) & Centigrade \\
\hline 14 & Martens heat distortion temperature & 210 & Centigrade \\
\hline 15 & $\begin{array}{l}\text { Test in oil : (1) At } 20^{\circ} \mathrm{C} \text { : } \\
\text { (2) At } 100^{\circ} \mathrm{C} \text { : }\end{array}$ & $\begin{array}{l}20 \mathrm{KV} / \mathrm{cm} \\
20 \mathrm{KV} / \mathrm{cm}\end{array}$ & $\mathrm{KV} / \mathrm{cm}$ \\
\hline
\end{tabular}


Table 2. Control parameters and their levels.

\begin{tabular}{clccc}
\hline Parameters & \multicolumn{1}{c}{ Process parameters } & \multicolumn{3}{c}{ Levels } \\
\cline { 3 - 5 } design & & 1 & 2 & 3 \\
\hline A & Tool nose radius / mm & 0.4 & 0.8 & NIL \\
B & Tool rake angle / degree & $(-6)$ & $(0)$ & $(+6)$ \\
C & Feed rate / (mm/rev.) & 0.05 & 0.1 & 0.2 \\
D & Cutting speed / (m/min.) \& rpm & $(55.42) 420$ & $(110.84) 840$ & $(159.66) 1210$ \\
E & Cutting environment & Dry (1) & Wet $(2)$ & Cooled (3) \\
F & Depth of cut / mm & 0.2 & 0.8 & 1.4 \\
\hline
\end{tabular}

Table 3. Experimental layout using $\mathrm{L}_{18}$ orthogonal array.

\begin{tabular}{ccccccccc}
\hline Expt. No. & A & B & C & D & E & F & --- & --- \\
\hline 1 & 1 & 1 & 1 & 1 & 1 & 1 & 1 & 1 \\
2 & 1 & 1 & 2 & 2 & 2 & 2 & 2 & 2 \\
3 & 1 & 1 & 3 & 3 & 3 & 3 & 3 & 3 \\
4 & 1 & 2 & 1 & 1 & 2 & 2 & 3 & 3 \\
5 & 1 & 2 & 2 & 2 & 3 & 3 & 1 & 1 \\
6 & 1 & 2 & 3 & 3 & 1 & 1 & 2 & 2 \\
7 & 1 & 3 & 1 & 2 & 1 & 3 & 2 & 3 \\
8 & 1 & 3 & 2 & 3 & 2 & 1 & 3 & 1 \\
9 & 1 & 3 & 3 & 1 & 3 & 2 & 1 & 2 \\
10 & 2 & 1 & 1 & 3 & 3 & 2 & 2 & 1 \\
11 & 2 & 1 & 2 & 1 & 1 & 3 & 3 & 2 \\
12 & 2 & 1 & 3 & 2 & 2 & 1 & 1 & 3 \\
13 & 2 & 2 & 1 & 2 & 3 & 1 & 3 & 2 \\
14 & 2 & 2 & 2 & 3 & 1 & 2 & 1 & 3 \\
15 & 2 & 2 & 3 & 1 & 2 & 3 & 2 & 1 \\
16 & 2 & 3 & 1 & 3 & 2 & 3 & 1 & 2 \\
17 & 2 & 3 & 2 & 1 & 3 & 1 & 2 & 3 \\
18 & 2 & 3 & 3 & 2 & 1 & 2 & 3 & 1 \\
\hline
\end{tabular}

The Taguchi mixed level design is selected as it is decided to keep two levels of tool nose radius. The remaining five parameters are studied at three levels. The two level parameter has $1 \mathrm{DOF}$ and the remaining five three level parameters have 10 DOF i.e., the total DOF required is $11\left[=\left(1 * 1+\left(5^{*} 2\right)\right]\right.$. The most appropriate orthogonal array in this case is $\mathrm{L}_{18}\left(2^{1} * 3^{7}\right)$ OA with 17 [= 18-1] DOF. The standard $\mathrm{L}_{18} \mathrm{OA}$ with the parameters assigned by using linear graphs is used. The unassigned columns are treated as error.

The process parameters, their designated symbol and ranges are also given in Table 2. The plan is made of 18 tests (array rows) in which the tool nose radius, tool rake angle, feed rate, cutting speed, cutting environment (dry, wet and cooled) and depth of cut are assigned to columns 1 to 6 respectively, as shown in Table 3. The cutting environment (dry, wet and cooled) is set during the machining of the rod, so as to get a comparative assessment of the performance of the cutting environment, which has not been studied before. The material removal rate (MRR) in $\mathrm{mm}^{3} / \mathrm{sec}$. is calculated using Equation 1.This is the volume of material being removed per unit time from the workpiece:

$$
\operatorname{MRR}=\frac{\frac{\pi}{4} \mathrm{D}^{2} \mathrm{~L}-\frac{\pi}{4} \mathrm{~d}^{2} \mathrm{~L}}{\mathrm{Tc}}
$$


where $\mathrm{T}_{\mathrm{C}}=\mathrm{L} / \mathrm{CN} ; N=$ spindle speed in $\mathrm{rpm} ; D=$ initial Dia in $\mathrm{mm} ; d=$ final dia in $\mathrm{mm}, L$ $=$ length in $\mathrm{mm}, C=$ feed rate in $\mathrm{mm} / \mathrm{rev}$. Table 4 shows the experimental results of the material removal rate.

Table 4. Test data summary for material removal rate.

\begin{tabular}{ccccc}
\hline \multirow{2}{*}{$\begin{array}{c}\text { Expt. } \\
\text { No. }\end{array}$} & \multicolumn{3}{c}{ Raw data } & $\begin{array}{c}\text { Average MRR } \\
\left(\mathrm{mm}^{3} / \mathrm{sec}\right)\end{array}$ \\
\cline { 2 - 4 } & $\mathrm{R} 1$ & $\mathrm{R} 2$ & $\mathrm{R} 3$ & \\
\hline 1 & 8.60 & 8.50 & 8.70 & 8.60 \\
2 & 145.00 & 145.02 & 144.95 & 144.99 \\
3 & 327.58 & 347.03 & 347.23 & 340.61 \\
4 & 36.24 & 36.24 & 36.24 & 36.24 \\
5 & 249.90 & 249.96 & 249.88 & 249.91 \\
6 & 106.02 & 105.86 & 105.90 & 105.93 \\
7 & 125.00 & 124.98 & 124.98 & 124.99 \\
8 & 52.96 & 52.99 & 52.97 & 52.97 \\
9 & 144.97 & 144.97 & 145.02 & 144.99 \\
10 & 104.42 & 104.38 & 104.40 & 104.40 \\
11 & 125.00 & 125.00 & 125.00 & 125.00 \\
12 & 73.57 & 73.58 & 73.55 & 73.57 \\
13 & 18.39 & 18.39 & 18.39 & 18.39 \\
14 & 208.72 & 208.92 & 208.92 & 208.85 \\
15 & 250.09 & 250.09 & 250.05 & 250.08 \\
16 & 180.00 & 180.04 & 180.00 & 180.01 \\
17 & 18.38 & 18.38 & 18.38 & 18.38 \\
18 & 275.93 & 275.87 & 275.75 & 275.85 \\
\hline
\end{tabular}

Table 5. Pooled ANOVA (Raw data: material removal rate).

\begin{tabular}{llllllll}
\hline Source & SS & DOF & V & F ratio & Prob. & SS $^{\prime}$ & P (\%) \\
\hline Tool nose radius(A) & 342 & 1 & 342 & Pooled & 0.595 & --- & --- \\
Tool rake angle(B) & 1739 & 2 & 869 & Pooled & 0.487 & --- & --- \\
Feed rate(C) & 129356 & 2 & 64678 & $54.41^{*}$ & 0.000 & 126978 & 26.179 \\
Cutting speed(D) & 45233 & 2 & 22616 & $19.03^{*}$ & 0.000 & 42855 & 8.835 \\
Cutting & 5404 & 2 & 2702 & Pooled & 0.116 & --- & --- \\
Environment(E) & 253033 & 2 & 126516 & $106.43^{*}$ & 0.000 & 253032 & 52.168 \\
Depth of cut(F) & & & & & & & \\
& 485034 & 53 & & & & 485034 & 100.00 \\
T & 49927 & 42 & 1189 & & & & \\
e (pooled) & & & & & & & \\
\hline
\end{tabular}

$\mathrm{SS}=$ sum of squares, DOF $=$ degrees of freedom, variance $(\mathrm{V})=(\mathrm{SS} / \mathrm{DOF})$,

$\mathrm{T}=$ total, $\mathrm{SS}^{\prime}=$ pure sum of squares, $\mathrm{P}=$ percent contribution, $\mathrm{e}=$ error,

$\mathrm{F}_{\text {ratio }}=($ V/error $)$, Tabulated F-ratio at $95 \%$ confidence level,

* Significant at $95 \%$ confidence level. 


\section{REGRESSION ANALYSIS}

A multiple linear regression equation is modeled for the relationship between processes parameters in a bid to evaluate the material removal rate for any combination of factor levels in a specified range. The functional relationship between the dependent output parameter and the independent variables under investigation is postulated by Eq. (2):

$$
\mathrm{Y}=\mathrm{K}\left(\mathrm{x}_{1}\right)^{\mathrm{a}}\left(\mathrm{x}_{2}\right)^{\mathrm{b}}\left(\mathrm{x}_{3}\right)^{\mathrm{c}}
$$

where $\mathrm{Y}$ is a dependent output variable such as the material removal rate. $\mathrm{x}_{1}, \mathrm{x}_{2}$ and $\mathrm{x}_{3}$ are independent variables such as the feed rate, cutting speed and depth of cut. The constants a, $\mathrm{b}$ and $\mathrm{c}$ are the exponents of the independent variables. To convert the above nonlinear equation into linear form, a logarithmic transformation is applied to the equation and written as Eq. (3):

$$
\log \mathrm{Y}=\log \mathrm{K}+\mathrm{a} \cdot \log \left(\mathrm{x}_{1}\right)+\mathrm{b} \cdot \log \left(\mathrm{x}_{2}\right)+\mathrm{c} \cdot \log \left(\mathrm{x}_{3}\right)
$$

This is one of the most popularly used data transformation methods for empirical model building. Now the above equation is written as Eq. (4):

$$
\eta=\beta_{0}+\beta_{1} x_{1}+\beta_{2} x_{2}+\beta_{3} x_{3}
$$

where $\eta$ is the true value of the dependent material removal rate on a logarithmic scale, $x_{1}$, $\mathrm{x}_{2}$ and $\mathrm{x}_{3}$ are respectively, the logarithmic transformation of the different parameters, while $\beta_{0}, \beta_{1}, \beta_{2}$ and $\beta_{3}$ are the corresponding parameters to be estimated. Due to the experimental error, the true response $\eta=y-\varepsilon$, where $y$ is the logarithmic transformation of the measured material removal rate parameter and $\varepsilon$ is the experimental error. For simplicity, the equation is rewritten as

$$
\hat{Y}=b_{0}+b_{1} x_{1}+b_{2} x_{2}+b_{3} x_{3}
$$

where $\hat{Y}$ is the predicted material removal rate value after logarithmic transformation and $b_{0}, b_{1}, b_{2}$ and $b_{3}$ are the estimates of the parameters, $\beta_{1}, \beta_{2}$, and $\beta_{3}$ respectively.

The values of $b_{0}, b_{1}, b_{2}$ and $b_{3}$ are found by linear regression analysis (second order model), which is conducted with MINITAB standard version software (MINITAB 15.0 for Windows) using the experimental data. The first order model for the material removal rate revealed a lack of fitness due to high prediction errors for the material removal rate. As a result, the below mentioned second order models were developed and their form is given below.

$\hat{Y}=b_{0}+b_{1} x_{1}+b_{2} x_{2}+b_{3} x_{3}+b_{12} x_{1} x_{2}+b_{13} x_{1} x_{3}+b_{23} x_{2} x_{3}+b_{11} x_{1}^{2}+b_{22} x_{2}^{2}+b_{33} x_{3}^{2}$

Here $\mathrm{x}_{1}, \mathrm{x}_{2}, \mathrm{x}_{3}$ are log of feed rate, cutting speed and depth of cut.

The empirical model developed by regression analysis for the material removal rate (MRR) is given below: 
$\mathrm{MRR}=0.005+1.52 \mathrm{x}_{1}+2.65 \mathrm{x}_{2}+1.08 \mathrm{x}_{3}+(-0.684) \mathrm{x}_{1} \mathrm{x}_{2}+(-0.347) \mathrm{x}_{1} \mathrm{x}_{3}+(-0.334) \mathrm{x}_{2} \mathrm{x}_{3}$ $+(-0.325) \mathrm{x}_{1}^{2}+(-0.651) \mathrm{x}_{2}^{2}+(-0.250) \mathrm{x}_{3}$

The predicted output values for the material removal rate are calculated with the help of the above equation and the given coefficients areas shown in Table 6 . The multiple regression coefficient $\mathrm{R}^{2}$ of the second-order model is found to be $99.5 \%$. On the basis of the multiple-regression coefficient $\left(\mathrm{R}^{2}\right)$, it can be concluded that the second order model is adequate in representing this process, as shown in Table 6 . Table 7 shows the analysis of variance in which the $\mathrm{P}$ value of $(0.000)$ for regression $<0.05$ indicates that at least one of the terms in the model has a significant effect on the mean response of the material removal rate (Montgomery, Peck, \& Vining, 2001).

Table 6. Empirical expressions developed by second order model.

\begin{tabular}{cc}
\hline Predictor & $\begin{array}{c}\text { Coefficient of material } \\
\text { removal rate }\end{array}$ \\
\hline $\mathrm{b}_{\mathrm{o}}$ & 0.005 \\
$\mathrm{x}_{1}$ & 1.52 \\
$\mathrm{x}_{2}$ & 2.65 \\
$\mathrm{x}_{3}$ & 1.08 \\
$\mathrm{x}_{1} \mathrm{x}_{2}$ & -0.684 \\
$\mathrm{x}_{1} \mathrm{X}_{3}$ & -0.347 \\
$\mathrm{x}_{2} \mathrm{X}_{3}$ & -0.334 \\
$\mathrm{x}_{1}{ }^{2}$ & -0.325 \\
$\mathrm{x}_{2}{ }^{2}$ & -0.651 \\
$\mathrm{x}_{3}{ }^{2}$ & -0.250 \\
$\mathrm{~S}=0.0490168$ & $\mathrm{R}-\mathrm{Sq}=99.5 \%, \mathrm{R}-\mathrm{Sq}(\mathrm{adj})=98$. \\
\hline
\end{tabular}

Table 7. ANOVA for second-order model (MRR).

\begin{tabular}{lccccc}
\hline \multicolumn{1}{c}{ Source } & DF & SS & MS & F & P \\
\hline Regression & 9 & 3.50924 & 0.38992 & 162.29 & 0.000 \\
Residual error & 8 & 0.01922 & 0.00240 & & \\
Total & 17 & 3.52846 & & & \\
\hline
\end{tabular}

Thus, it can be stated that the empirical equation built by using the second order model can be used. The relative error between the predicted and measured observed values for the material removal rate is calculated and presented in Table 7. The significance of the predictors, shown in Table 6, is also analyzed further, as shown in Table 8.

\section{Goodness of Fit for Surface Roughness and Material Removal Rate}

To test whether the discrepancies between the observed and expected frequencies can be attributed to chance, we use the statistics for test of goodness of fit for the material removal rate as given by Eq. 7 .

$$
\chi^{2}=\sum_{i=1}^{k} \frac{(O i-E i)^{2}}{E i}
$$


The criterion chosen for either accepting or rejecting the null hypothesis is:

If $\chi 2>8.672$ (tabulated value). Reject the null hypothesis

Table 8. Comparison between experimental and predicted values of material removal rate.

\begin{tabular}{cccc}
\hline & \multicolumn{3}{c}{ Material removal rate } \\
\cline { 2 - 4 } Expt. No. & Prediction value & Experimental value & \% Error \\
\hline 1 & 7.674 & 8.60 & -12.067 \\
2 & 151.705 & 144.99 & 4.426 \\
3 & 394.457 & 340.61 & 13.651 \\
4 & 37.670 & 36.24 & 3.796 \\
5 & 228.560 & 249.91 & -9.341 \\
6 & 96.161 & 105.93 & -10.159 \\
7 & 129.419 & 124.99 & 3.422 \\
8 & 54.954 & 52.97 & 3.610 \\
9 & 153.109 & 144.99 & 5.303 \\
10 & 108.893 & 104.40 & 4.126 \\
11 & 129.419 & 125.00 & 3.414 \\
12 & 77.446 & 73.57 & 5.003 \\
13 & 19.011 & 18.39 & 3.266 \\
14 & 188.799 & 208.85 & -10.620 \\
15 & 229.615 & 250.08 & -8.913 \\
16 & 168.655 & 180.01 & -6.733 \\
17 & 19.142 & 18.38 & 3.981 \\
18 & 247.742 & 275.85 & -11.346 \\
\hline
\end{tabular}

Table 9 shows that $\chi^{2}=1.1078$ for the material removal rate for 17 degrees of freedom, where the degree $(\mathrm{s})$ of freedom is given by: (rows-1) $\times($ col-1) $=(18-1) \times(2-1)=$ 17. Therefore, analysis of the data does suggest that the perception is correct with a $95 \%$ confidence level. Otherwise, there is reason to believe that the program gives correct output, as shown in Table 9.

\section{PARTICLE SWARM OPTIMIZATION}

PSO is a global optimization technique that has been developed by Kennedy and Eberhardt (1995). The particle swarm intelligence technique combines social psychology principles in socio-cognition human agents with evolutionary computations. PSO was motivated by the behavior of organisms such as fish schooling and bird flocking, in order to guide swarms of particles towards the most promising regions of the search space. Generally, PSO is characterized as a simple concept, that is easy to implement and computationally efficient. Unlike the other heuristic techniques, PSO has a flexible and well-balanced mechanism to enhance the global and local exploration abilities. Thus, a PSO algorithm can be employed to solve an optimization problem. Each particle in the swarm represents a candidate solution to the optimization problem. In a PSO, each particle moves to the new position and makes use of the best position encountered by itself and the best position of its neighbors to position itself towards the global minimum. 
Table 9. Statistics for test of goodness of fit of material removal rate

\begin{tabular}{cccc}
\hline & \multicolumn{3}{c}{ Material removal rate } \\
\cline { 2 - 4 } Expt. No. & Observed value & Expected value & $\left(\mathrm{O}_{\mathrm{i}}-\mathrm{E}_{\mathrm{i}}\right)^{2} / \mathrm{E}_{\mathrm{i}}$ \\
\hline 1 & 8.60 & 7.674 & 0.1117 \\
2 & 144.99 & 151.705 & 0.2972 \\
3 & 340.61 & 394.457 & 7.3506 \\
4 & 36.24 & 37.670 & 0.0542 \\
5 & 249.91 & 228.560 & 1.9943 \\
6 & 105.93 & 96.161 & 0.9924 \\
7 & 124.99 & 129.419 & 0.1515 \\
8 & 52.97 & 54.954 & 0.0716 \\
9 & 144.99 & 153.109 & 0.4305 \\
10 & 104.40 & 108.893 & 0.1853 \\
11 & 125.00 & 129.419 & 0.1508 \\
12 & 73.57 & 77.446 & 0.1939 \\
13 & 18.39 & 19.011 & 0.0202 \\
14 & 208.85 & 188.799 & 2.1294 \\
15 & 250.08 & 229.615 & 1.8239 \\
16 & 180.01 & 168.655 & 0.7644 \\
17 & 18.38 & 19.142 & 0.0303 \\
18 & 275.85 & 247.742 & 3.189 \\
Average & & & $\chi 2=1.1078$ \\
\hline
\end{tabular}

*Test level of significance: $\propto=95 \%$

The principle of the PSO algorithm is as follows (Esmin, Lambert-Torres, \& de Souza, 2005). The PSO considers a swarm $S$ containing $n$ particles $(\mathrm{S}=1,2 \ldots \ldots \mathrm{N})$ in a $d$ dimensional continuous solution space. The position and velocity of individual si are represented as the vectors $x_{i}=\left(x_{i 1} \ldots \ldots \ldots x_{i d}\right)$ and $v_{i}=\left(v_{i 1} \ldots \ldots \ldots v_{i d}\right)$, respectively. A bird adjusts its position in order to find a better position, according to its own experience and the experience of its companions. Using the information, the updated velocity of individual $i$ is modified using Eq. 8.

$$
\mathrm{v}_{\text {id }}{ }^{\mathrm{t}+1}=\mathrm{W} \mathrm{v}_{\mathrm{id}}^{\mathrm{t}}+\mathrm{c}_{1} \mathrm{r}_{1} *\left(\mathrm{P}_{\mathrm{id}}{ }^{\mathrm{t}}-\mathrm{X}_{\mathrm{id}}^{\mathrm{t}}\right)+\mathrm{c}_{2} \mathrm{r}_{2} *\left(\mathrm{p}_{\mathrm{gd}}{ }^{\mathrm{t}}-\mathrm{x}_{\mathrm{id}}^{\mathrm{t}}\right)
$$

where

$\mathrm{v}_{\text {id }}^{\mathrm{t}}$ : a component in dimension $\mathrm{d}$ of the $\mathrm{i}^{\text {th }}$ particle velocity in iteration $\mathrm{t}$

$\mathrm{x}_{\text {id: }}^{\mathrm{t}}$ a component in dimension $\mathrm{d}$ of the $\mathrm{i}^{\text {th }}$ particle position in iteration $\mathrm{t}$

$\mathrm{c}_{1}, \mathrm{c}_{2}$ : weight factors

$\mathrm{p}_{\mathrm{i}}$ : best position achieved so far by particle $\mathrm{i}$

$p_{\mathrm{g}}$ : best position achieved so far by neighbors of particle $i$

$\mathrm{r}_{\mathrm{i}}, \mathrm{r}_{2}$ : random factors in range $[0,1]$

w: inertia weight 


\section{Control Parameters of PSO}

Number of generations $=50$

Number of particles $(\mathrm{N})=5$

$\mathrm{c} 1=0.8$

$\mathrm{c} 2=2$

$\mathrm{w}=0.9$

Coding of particle $=$ binary

Number of bits per parameter is taken as 4 .

Number of significant parameters $=3($ feed rate $(C)$ in $\mathrm{mm} / \mathrm{rev}$., cutting speed (D) in $\mathrm{m} / \mathrm{min}$. and depth of cut $(\mathrm{F})$ in $\mathrm{mm}$ )

Total length of particle $=12$

Fitness parameter: minimization of surface roughness

\section{Coding of Particles}

Generate each particle using binary coding. Here the binary format particle is decoded by using Eq. 9.

$$
X_{i}=X_{i}^{l}+\frac{X_{i}^{U}-X_{i}^{L}}{2^{n}-1} S_{i}
$$

where $\mathrm{X}_{\mathrm{i}}$ is the decoded feed, cutting speed or depth of cut, $X_{i}^{l}$ is the lower limit of feed, cutting speed or depth of cut, $X_{i}^{u}$ is the upper limit of feed cutting speed or depth of cut, and $n$ is the substring length $(=4)$ and $S_{i}$ is the decoded value of the $i^{\text {th }}$ chromosome. Accuracy is given by Eq. 10:

$$
\text { Accuracy }=\frac{X^{U}-X^{L}}{X^{n}-1}
$$

Figure 1 and Table 10 show the flow diagram and algorithm of PSO.

Table 10. Algorithm of PSO .

\section{Algorithm}

Step 1: Generate the initial swarm involving $N$ particles at random.

Step 2: Generate the initial velocity randomly.

Step 3: Find the best solution that has been achieved so far by that particle and the best value obtained so far by any particle in the neighborhood of that particle.

Step 4: Update the velocity and position

Step 5: If the termination condition is satisfied, stop.

Otherwise, go to Step 3.

\section{RESULTS AND DISCUSSION}

Experiments are performed on a turning machine according to the $\mathrm{L}_{18}$ orthogonal array shown in Table 3. Table 4 shows the experimental results of the material removal rate. The 
pooled version of ANOVA of the raw data for the material removal rate is given in Table 5. From Table 5, it is clear that parameters C, D and F significantly affect both the mean and variation in the material removal rate value. The percent contributions of parameters, as quantified under column $\mathrm{P}$ of Table 5, reveal that the influence of the depth of cut on the material removal rate is significantly larger than the feed rate and cutting speed. The percent contributions of depth of cut $(52.168 \%)$, feed rate $(26.179 \%)$ and cutting speed $(8.838 \%)$ in affecting the variation of the material removal rate are significantly larger ( $95 \%$ confidence level) than the contribution of the other parameters, as shown in Table 6(A).

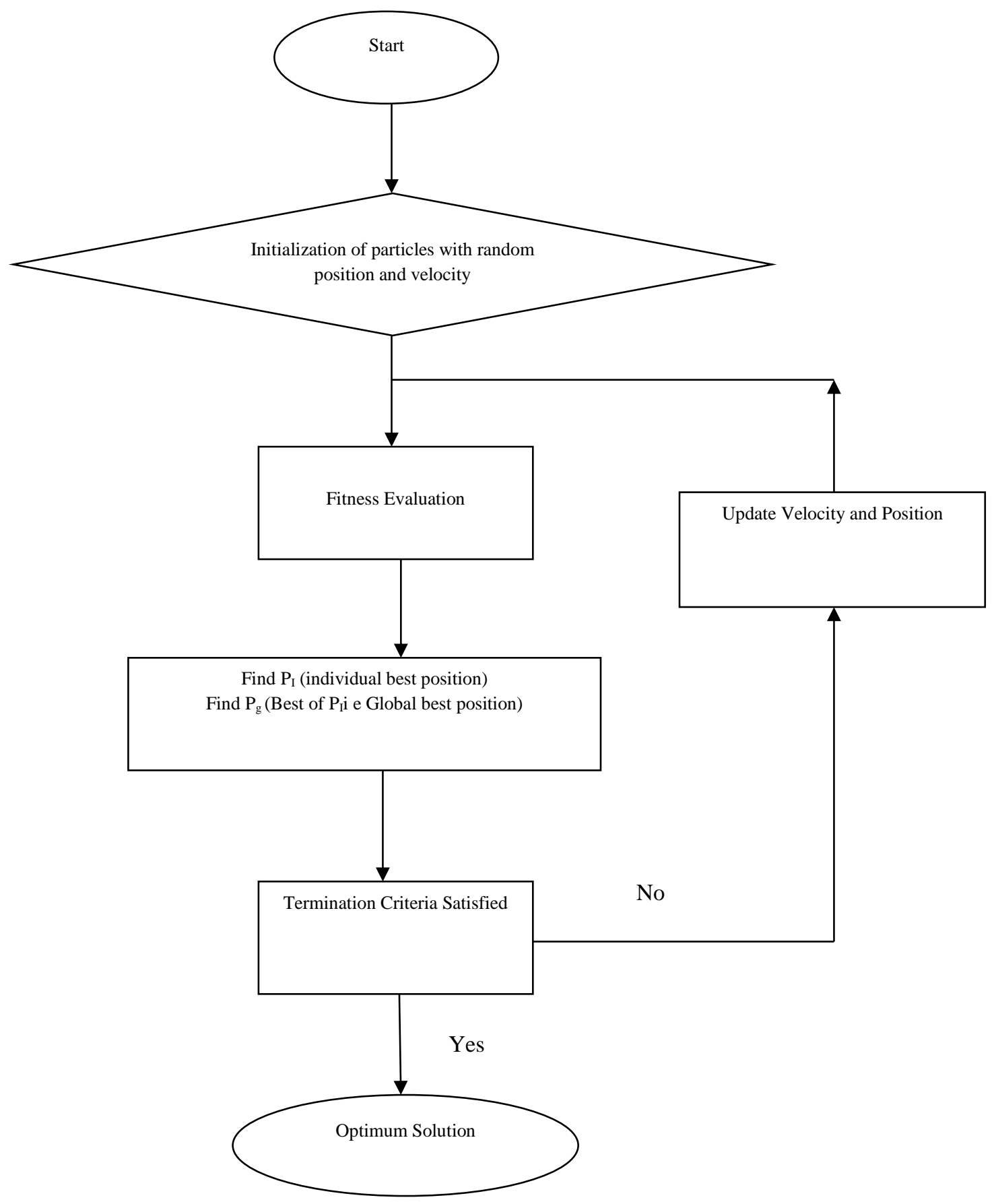

Figure 1. Flow chart of PSO 
The PSO code is developed using MATLAB. The input machining parameter levels are fed to the PSO program. It is possible to determine the conditions at which the turning operation has to be carried out in order to get the optimum material removal rate. Figure 2 shows the MRR versus no. of iterations. Table 11 shows the performance of the material removal rate with respect to input machining parameters for PSO. It has been found that the maximum value of the material removal rate is $394.33 \mathrm{~mm}^{3} / \mathrm{sec}$., which is at feed rate $(0.200 \mathrm{~mm} / \mathrm{rev})$, cutting speed $(159.58 \mathrm{~m} / \mathrm{min})$ and depth of cut $(1.3996 \mathrm{~mm})$. Hence, it can be concluded from the optimization results of the PSO program that it is possible to select a combination of feed rate, cutting speed and depth of cut to achieve the required material removal rate. The application of a PSO approach to obtain the optimal machining conditions will be very useful at the computer-aided process planning (CAPP) stage in the production of high-quality goods with tight tolerances by a variety of automated machining operations and in adaptive control machine tools. With the known boundaries of the material removal rate and machining conditions, machining can be performed with a relatively high rate of success with the selected machining conditions.

Table 11. Output values of the PSO with respect to input machining parameters.

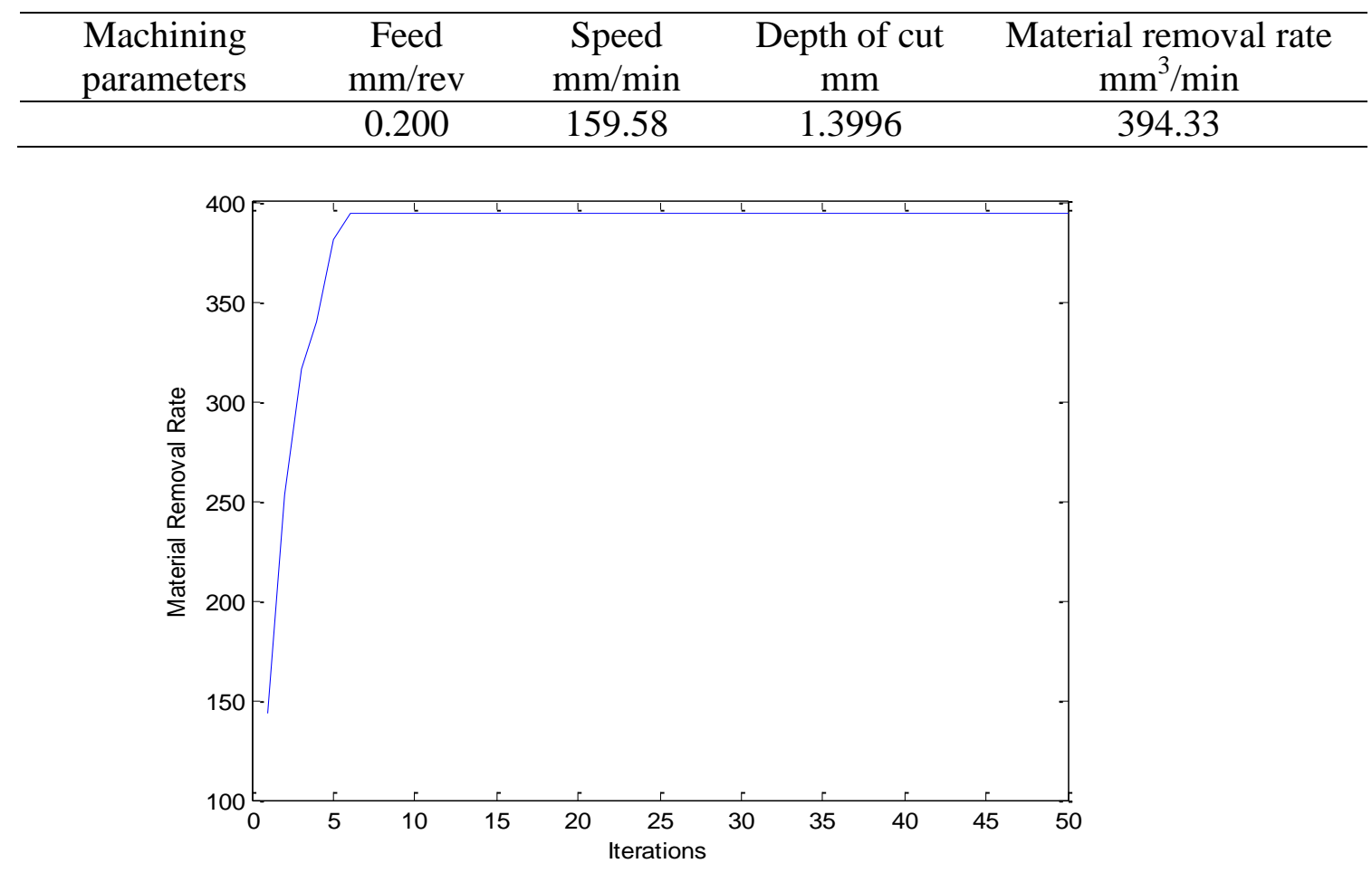

Figure 2. Performance of PSO.

\section{CONCLUSIONS}

The turning test is performed on GFRP using a PCD tool. The Taguchi $\mathrm{L}_{18}$ orthogonal array is used to perform experiments to analyze the MRR. In this paper, an approach based on particle swarms is used to solve the optimization problem for maximizing MRR. The simulation results show that the approach quickly converges. PSO is an efficient and effective optimization tool for finding the optimum machining parameters for maximizing MRR. The results give a positive indication of the potential offered by PSO. It can be concluded that better optimization of cutting parameters is necessary to obtain a high 
MRR. The maximum value of the material removal rate is found to be $394.33 \mathrm{~mm}^{3} / \mathrm{sec}$., which is at feed rate $(0.200 \mathrm{~mm} / \mathrm{rev})$, cutting speed $(159.58 \mathrm{~m} / \mathrm{min})$ and depth of cut (1.3996mm).

\section{ACKNOWLEDGMENTS}

This work is supported by the National Institute of Technology Kurukshetra through a scholarship and financial support. This financial support is gratefully acknowledged.

\section{REFERENCES}

Abido, M. A. (2001). Particle swarm optimization for multi machine power system stabilizer design. IEEE Conference, 3, 1346-1351.

Abrate, S. \& Walton, D. A. (1992). Machining of composite materials (a two part review). Composites Manufacturing, 3(2), 75-94.

Adam Khan, M., \& Senthil Kumar, A. (2011). Machinability of glass fibre reinforced plastic (GFRP) composite using alumina-based ceramic cutting tools. Journal of Manufacturing Processes, 13, 67-73.

Adebisi, A. A., Maleque, M. A., \& Rahman, M. M. (2011). Metal matrix composite brake rotor: historical development and product life cycle analysis. International Journal of Automotive and Mechanical Engineering, 4, 471-480.

Bachtiar, D., Sapuan, S. M., \& Hamdan, M. M. (2010). Flexural properties of alkaline treated sugar palm fibre reinforced epoxy composites. International Journal of Automotive and Mechanical Engineering, 1, 79-90.

Bhaskar, H. B., \& Sharief, A. (2012). Effect of solutionizing on dry sliding wear of Al2024-Beryl metal matrix composite. Journal of Mechanical Engineering and Sciences, 3, 281-290.

Dautenhahn, K. (2002). Swarm intelligence. Genetic Programming and Evolvable Machines, 3(1), 93-97.

Dhavamani, C. \& Alwarsamy, T. (2011). Optimization of cutting parameters of composite materials using genetic algorithm. European Journal of Scientific Research, 63(2), 279-285.

Esmin, A. A., Lambert-Torres, G., \& de Souza, A. C. Z. (2005). A hybrid particle swarm optimization applied to loss power minimization. IEEE Trans. Power Systems, 20(2), 859-866.

Gordon, S. \& Hillery, M. T. (2002). A review of the cutting of composite materials. Proceedings of the Institution of Mechanical Engineers, 217, 35-45.

Hariprasad, T., Dharmalingam, G., \& Praveen Raj, P. (2013). A study of mechanical properties of banana-coir hybrid composite using experimental and fem techniques. Journal of Mechanical Engineering and Sciences, 4, 518- 531.

Hassan, R., Cohanim, B., \& de Weck, O. (2004) A comparison of particle swarm optimization and the genetic algorithm. American Institute of Aeronautics and Astronautics, 1-13.

Hu, N. S. \& Zhang, L. C. (2004). Some observations in grinding unidirectional carbon fibre-reinforced plastics. Journal of Materials Processing Technology, 152, 333338. 
Hussain, S. A., Pandurangadu, V., \& Palanikumar, K. (2010). Surface roughness analysis in machining of GFRP composite by carbide tool (K20). European Journal of Scientific Research, 41(1), 84-98.

Janardhan, P. (2005). Tool wear of diamond interlocked tools in routing of CFRP composites (Master's thesis). Wichita State University.

Jeffrey, K. J. T., Tarlochan, F., \& Rahman, M. M. (2011). Residual strength of chop strand mats glass fiber/epoxy composite structures: effect of temperature and water absorption. International Journal of Automotive and Mechanical Engineering, 4, 504-519.

Kennedy, J. \& Eberhart, R. (1995). Particle swarm optimization. In Proc. IEEE Int. Conf. Neural Networks (ICNN`95), Perth, Australia, 4: 1942-1948.

Khan, M. A. R., Rahman, M. M., Kadirgama, K., Maleque, M. A., \& Ishak, M. (2011). Prediction of surface roughness of Ti-6Al-4V in electrical discharge machining: a regression model. Journal of Mechanical Engineering and Sciences, 1, 16-24.

Konig, W., Wulf, Ch., Grab, P., \& Willerscheid, H. (1985). Machining of fibre reinforced plastics. CIRP Annals, 34, 537-548.

Kumar, S., Meenu, Satsangi, P. S. \& Sardana, H. K. (2012a). Multiple regression model for cutting force in turning UD-GFRP using polycrystalline diamond cutting tool. International Journal of Advanced Engineering Technology, 3(1), 108-112.

Kumar, S., Meenu, Satsangi, P. S., \& Sardana, H. K. (2012b). Optimization of surface roughness in turning unidirectional glass fiber reinforced plastics (UD-GFRP) composites using polycrystalline diamond (PCD) cutting tool. Indian Journal of Engineering \& Materials Sciences, 19, 163-174.

Lee, E. S. (2001). Precision machining of glass fibre reinforced plastics with respect to tool characteristics. International Journal of Manufacturing Technology, 17, 791-798.

Montgomery, D. C., Peck, E. A., \& Vining, G. 2001. Introduction to linear regression analysis. USA: Wiley.

Murthy, B. R. N., Rodrigues, L. L. R., \& Anjaiah, D. (2012). Process parameters optimization in GFRP drilling through integration of Taguchi and response surface methodology. Research Journal of Recent Sciences, 1(6), 7-15.

Palanikumar, K. (2008). Application of Taguchi and response surface methodologies for surface roughness in machining glass fibre reinforced plastics by PCD tooling. International Journal of Manufacturing Technology, 36, 19-27.

Palanikumar, K., Latha, B., Senthilkumar, V. S., \& Karthikeyan, R. (2009). Multiple performance optimizations in machining of GFRP composites by a PCD tool using non-dominated sorting genetic algorithm (NSGA-II). Metals and Materials International, 15(2), 249-258.

Paulo Davim, J. \& Reis, P. (2004). Multiple regression analysis (MRA) in modeling milling of glass fibre reinforced plastics (GFRP). International Journal Manufacturing Technology Management, 6(1/2), 85-197.

Ravi Sankar, H., Srikant, R. R., Vamsi Krishna, P., Bhujanga Rao, V., \& Bangaru Babu, P. (2013). Estimation of the dynamic properties of epoxy glass fabric composites with natural rubber particle inclusions. International Journal of Automotive and Mechanical Engineering, 7, 968-980.

Suresh Kumar Reddy, N. \& Venkateswara Rao, P. (2005). A genetic algorithmic approach for optimization of surface roughness prediction model in dry milling. Machine Science and Technology, 9, 63-84. 
Umar, A. H., Zainudin, E. S., \& Sapuan, S. M. (2012). Effect of accelerated weathering on tensile properties of kenaf reinforced high-density polyethylene composites. Journal of Mechanical Engineering and Sciences, 2, 198-205.

Verma, R. K. (2012). Fuzzy rule based optimization in machining of glass fiber reinforced polymer (GFRP) composites (M.Tech thesis). National Institute of Technology, Rourkela.

Zhang, H. \& Ishikawa, M. (2008). Particle swarm optimization with diversive curiosity: an endeavor to enhance swarm intelligence. IAENG International Journal of Computer Science, 35(3), 35-3-04.

Zhou, J. L., Duan, Z. C., Li, Y., Deng, J. C., \& Yu, D. Y. (2006). PSO-based neural network optimization and its utilization in a boring machine. Journal of Materials Processing Technology, 178(1-3), 19-23. 